\title{
18-month-olds use different cues to categorize plants and artifacts
}

\author{
Stella C. Gerdemann ${ }^{1,2}$ \& Annie E. Wertz ${ }^{3}$ \\ ${ }^{1}$ Department of Early Child Development and Culture, Faculty of Education, Leipzig \\ University, Jahnallee 59, 04109 Leipzig, Germany \\ ${ }^{2}$ Leipzig Research Center for Early Child Development, Leipzig University, Jahnallee 59, \\ 04109 Leipzig, Germany
}

${ }^{3}$ Max Planck Institute for Human Development, Max Planck Research Group Naturalistic Social Cognition, Lentzeallee 94, 14195 Berlin, Germany

In Press, Evolution and Human Behavior.

Correspondence: Correspondence for this article should be addressed to stella.gerdemann@unileipzig.de

Acknowledgements: This work was supported by funding from the Max Planck Society awarded to A. E. Wertz. We thank Heidi Nassimi and Dulce Erdt for their help throughout this project. In addition, we thank Carmen Kaiser, Mayara Machado da Silva, Kristia Pamungkas, Theresa Pokojski, Blanca Vidal Orga, Chelsea Wright, Jasmin Eichelsdörfer, Marie Wiedenhöft, and Lena Marie Krippner for their help with coding and data collection. We also thank Camille Rioux and Connair Russell for providing helpful feedback on previous versions of this paper. We especially thank the infants and their parents who participated in this study. Parts of this work were published as the Master's thesis of the first author. 
Conflicts of Interest: None to declare.

Data Availability Statement: The data and analysis scripts are available through the Open

Science Framework: https://osf.io/5knxr/?view_only=ec1d247f3174446b8fa2b1be2e985722. 


\begin{abstract}
One key adaptive problem that humans had to solve was to identify safe plants while avoiding dangerous ones. The ability to reliably categorize plants was likely critical to accomplishing this task and avoid confusing non-toxic plants with similar-looking toxic ones. Here, we investigated which cues 18-month-old infants (Study 1, $N=40$ ) from Germany, and adults (Study 2, N=145) recruited online use to categorize plants and manmade artifacts. To this end, in Study 1, we presented infants with plants with different leaf shapes in brightly colored pots and feature-matched artifacts that had the same variation in shape and color as the plants. The results of the categorization task indicate that infants relied on variation in leaf shape to categorize plants more than they relied on similar variation in shape to categorize artifacts. In Study 2, using a modified version of the task from Study 1, we found that adults were less willing to categorize plants using features other than leaf shape, while they were more willing to do so for artifacts. We conclude that infants use different features to categorize plants and artifacts and that aspects of this categorization strategy persist into adulthood. The features infants use to categorize plants would have reliably differentiated between plant types over ancestral time and thus reliance on these features may be based on their conceptual relevance to plants.
\end{abstract}

Keywords: Evolutionary psychology; Infancy; Categorization; Plants; Conceptual development 


\section{8-month-olds use different cues to categorize plants and artifacts}

\section{Introduction}

Millions of animal species depend on plants for survival. Any species that consumes plant resources must be able to extract nutrients while mitigating the effects of the myriad toxins and mechanical defenses that plants have evolved to protect themselves from herbivores (Chen, 2008; Fürstenberg-Hägg et al., 2013; Mithöfer \& Boland, 2012; Palo \& Robbins, 1991). Consequently, a dizzying array of design features have evolved across the animal kingdom to cope with the costs and benefits of plant foraging (e.g., Freeland \& Janzen, 1974; Kingsbury, 1983; Knolhoff \& Heckel, 2014; Perry, 2011; Rozin \& Kalat, 1971). Humans have not been exempted from this process. For example, humans have enzymatic detoxification pathways that are specialized to processing plant toxins (Hagen et al., 2009) and mechanisms like pregnancy sickness and food aversions that protect against toxic and teratogenic plant compounds (Placek et al., 2017; Placek \& Hagen, 2015; Profet, 1992). Similarly, food neophobia in young children is particularly strong for plant foods (e.g., vegetables and fruits), which would protect young children from ingesting plant toxins during the time when they first become independently mobile (Cashdan, 1994, 1998; Dovey et al., 2008; Rioux, 2019).

Recent work with infants has begun to uncover additional cognitive mechanisms that appear to be designed for facilitating human interactions with plants. Infants initially avoid making physical contact with plants, which would reduce their exposure to harmful plant defenses (e.g., Wertz \& Wynn, 2014a; Włodarczyk et al., 2018), differentially seek out social information from adults (Elsner \& Wertz, 2019), and selectively learn about plant properties such as edibility and safety to touch (Wertz \& Wynn, 2014b; Włodarczyk et al., 2020). This network of cognitive mechanisms has been dubbed Plant Learning and Avoiding Natural Toxins, or PLANT (Wertz, 2019). Evolutionary modeling confirms that social learning 
mechanisms would be expected to evolve in environments with toxic plants (Oña et al., 2019). However, this modeling work also points to an important caveat regarding the PLANT social learning mechanisms. Specifically, social learning can be costly when edible plants are confused with toxic plants, suggesting that accurately categorizing plants - and thereby differentiating between plant types that can look quite similar to each other-is a critical component of PLANT.

Correspondingly, there is already some evidence that infants can distinguish between different types of plants (Wertz \& Wynn, 2019). In these studies, after watching an actor eat fruits from one type of plant (e.g., with orange fruits and round leaves), 18-month-olds were presented with two new plants — one of the same type (e.g., with orange fruits and round leaves) and one of a different type (e.g., with purple fruits and pointed leaves) — and asked to choose which one they could eat. Infants in these studies reliably chose the same type of plant. These studies, however, did not directly address which features infants use to categorize plants, and whether they use the same or different features to categorize artifacts. Therefore, it remains unclear whether infants' categorization of plants is informed by the conceptual relevance of different leaf shapes to distinguishing between plant types (see Gelman, 1990; Keil, 1989). In this case, we might expect that differences in leaf shape would be relevant to categorize plants, but not necessarily other kinds of objects. Alternatively, infants might distinguish between plants with different leaf shapes based on the perceptual dissimilarity between lower-level shape features. In this case, infants would likely categorize many kinds of objects based on leaf-shape-like features, and not show selectivity for categorizing plants.

Previous work has shown that infants possess remarkable abilities to categorize objects according to both perceptually and conceptually relevant features. For instance, by 9 to 11 months, infants are able to differentiate between objects such as animals and furniture when perceptual differences between these objects are held minimal (Mandler \& 
McDonough, 1993; Pauen, 2002), and selectively generalize properties such as drinking to animals and driving to vehicles respectively (Mandler \& McDonough, 1996; McDonough \& Mandler, 1998). Moreover, by the age of 18 months, infants categorize animals according to texture, rather than size, whereas they show no preference for texture-based categorization of artifacts (Booth et al., 2005; Booth \& Waxman, 2002b). Similarly, young children by age 2 rely on function to categorize artifacts (Kemler Nelson et al., 2000; see also Diesendruck et al., 2003; Truxaw et al., 2006), and by age 3 toddlers use variation in color and substance to categorize foods, but not toys (Lavin \& Hall, 2001; Macario, 1991). The overall conclusion from this line of work is that infants and young children are sensitive to a range of conceptual differences between objects and use them for categorization and generalization, while also relying on perceptual similarity.

On the other hand, proponents of perceptual-associationist accounts of conceptual development have challenged these findings and proposed that infants before the third year of life attend primarily to perceptual features of objects as a basis for categorization regardless of the conceptual relevance of the features (Jones et al., 1991; Jones \& Smith, 2002; Landau et al., 1988; Smith et al., 1996 see also Sloutsky, 2003). According to this view, a selective reliance on texture to categorize animals and on function to categorize artifacts, does not emerge in young children's categorization until they are above age 3 , and, even at this age, young children's categorization is thought to be mainly based on perceptual similarities, for instance in shape (Jones \& Smith, 2002; Smith et al., 1996). In support of this view, young children do often favor salient perceptual features for categorization and generalization in the presence of conceptually relevant properties, for instance by relying on similarity in appearance over function when categorizing artifacts (Smith et al., 1996). It is important to note that many of these studies have examined categorization in the presence of object names, as a large body of work suggests that infants and young children use shared names to identify 
relevant properties for categorization and generalization (Booth \& Waxman, 2002a; S. A. Gelman \& Markman, 1986; Graham et al., 2004; Markman, 1989). To our knowledge no previous study has examined whether infants use conceptually relevant features to categorize plants.

Here, we examined which features 18-month-olds use to categorize plants, and whether they use the same or different features to categorize artifacts. In Study 1, 18-month-olds were tested in a categorization task (based on Booth et al., 2005; Booth \& Waxman, 2002a; Nazzi \& Gopnik, 2001) with two between-subjects conditions (plant or artifact). In one condition, infants were presented with artificial plants in brightly colored pots, while infants in the other condition were presented with "feather duster" artifacts with brightly colored rods. The top parts of both plants and artifacts were made of the same materials, yet on the plants, the top part was designed to look like leaf shapes, while on the artifacts the same materials were designed to look like the "duster" part of the objects. In the categorization task, infants were prompted to match one object out of two to a named target. One of the objects was dissimilar from the target in terms of pot / rod color, but shared subtle shape cues with it (i.e., the leaf shape of the plants and the "duster" part of the artifacts). The other object was similar to the target in pot / rod color but differed from it in subtle shape cues. Thus, in both plant and artifact conditions, categorizing objects based on shared subtle shape cues required overriding the pull to categorize objects based on a salient perceptual feature, namely similarity in pot / rod color.

We hypothesized that if infants attend to conceptually relevant features to categorize plants, infants will rely more on subtle shape cues in the plant than in the artifact condition. Thus, we hypothesized that infants would overlook a salient perceptual feature in the plant, but not the artifact condition. We predicted that infants would attend to subtle shape cues for plants because distinguishing between plant species, which can look quite similar to one 
another, is a key component of successfully deploying learned knowledge about plants (Oña et al., 2019). Broadly speaking, this prediction is consistent with a view on conceptual development, according to which infants integrate perceptual and conceptual information for categorization early in development (e.g., Booth et al., 2005).

In addition to the categorization task, we collected measures on infants' vocabulary size (Szagun et al., 2009), and prior experience with plants via the Plant Experience Questionnaire (Wertz \& Wynn, 2014a, 2014b). We collected these measures to assess whether infants with a larger vocabulary might be more likely to attend to subtle shape cues overall (see Jones \& Smith, 2002), and to examine if there is a relationship between infants' prior experience with plants and their tendency to attend to conceptually relevant features to categorize them.

In Study 2, we modified the procedure of Study 1 to examine whether adults also show evidence of different categorization strategies for plants and artifacts.

\section{Study 1}

\subsection{Methods}

This study was pre-registered Open Science Framework and approved by the Ethics Committee of the Max Planck Institute for Human Development.

\subsubsection{Participants}

The final sample included $N=40$ healthy full-term 18-month-olds (19 girls, mean age $=18$ months and 14 days; range $=17$ months and 19 days to 19 months and 0 days) who were recruited from a large city in Germany. We chose this sample size based on previous studies which used similar tasks with infants this age, for which sample sizes typically range between 12 and 24 infants per cell (Booth \& Waxman, 2002a; Nazzi \& Gopnik, 2001). A sensitivity power analysis conducted with the R-package simr (Green \& MacLeod, 2016) based on 1000 iterations estimated that with this sample size, we had approximately $1-$ beta $=0.8$ power to detect an effect of $\log$ odds ratio $=1$ (or odds ratio $=2.7$ ) for the main effect of condition, 
which is considered a small to medium effect (Chen et al., 2010). Infants whose parents stated that their child had heard at least 50\% German since birth were invited to participate. An additional $N=16$ infants were excluded from the final analyses for the following preregistered reasons: fussiness $(N=10)$, and more than two choice phases with no clear choice $(N=6) . N=1$ additional infant was excluded from the sample due to pre-term birth (discovered after being recruited to participate).

\subsubsection{Stimuli}

The stimuli consisted of two sets of five artificial plants and two sets of five novel artifacts (see Fig. 1). We used artificial plants, because previous studies have shown that infants treat real and artificial plants quite similarly (e.g., Elsner \& Wertz, 2019; Wertz \& Wynn, 2014a), and we wanted the plants to retain the same appearance over the entire study period. Both plants and artifacts featured a sub-part (i.e., plants' leaves and the "duster" part of the artifacts), which were constructed of the same number and kind of artificial plant leaves (see also Section S1.1.). We conducted a stimulus validation study with adults to ensure that the visual similarity of the objects was matched across conditions (see Supplementary Materials, Study 1a, Section S2). The leaves of the plants were different shades of green and presented growing out of pots, while on the artifacts the same leafy materials were attached to wooden rods and colored in gold and silver. 


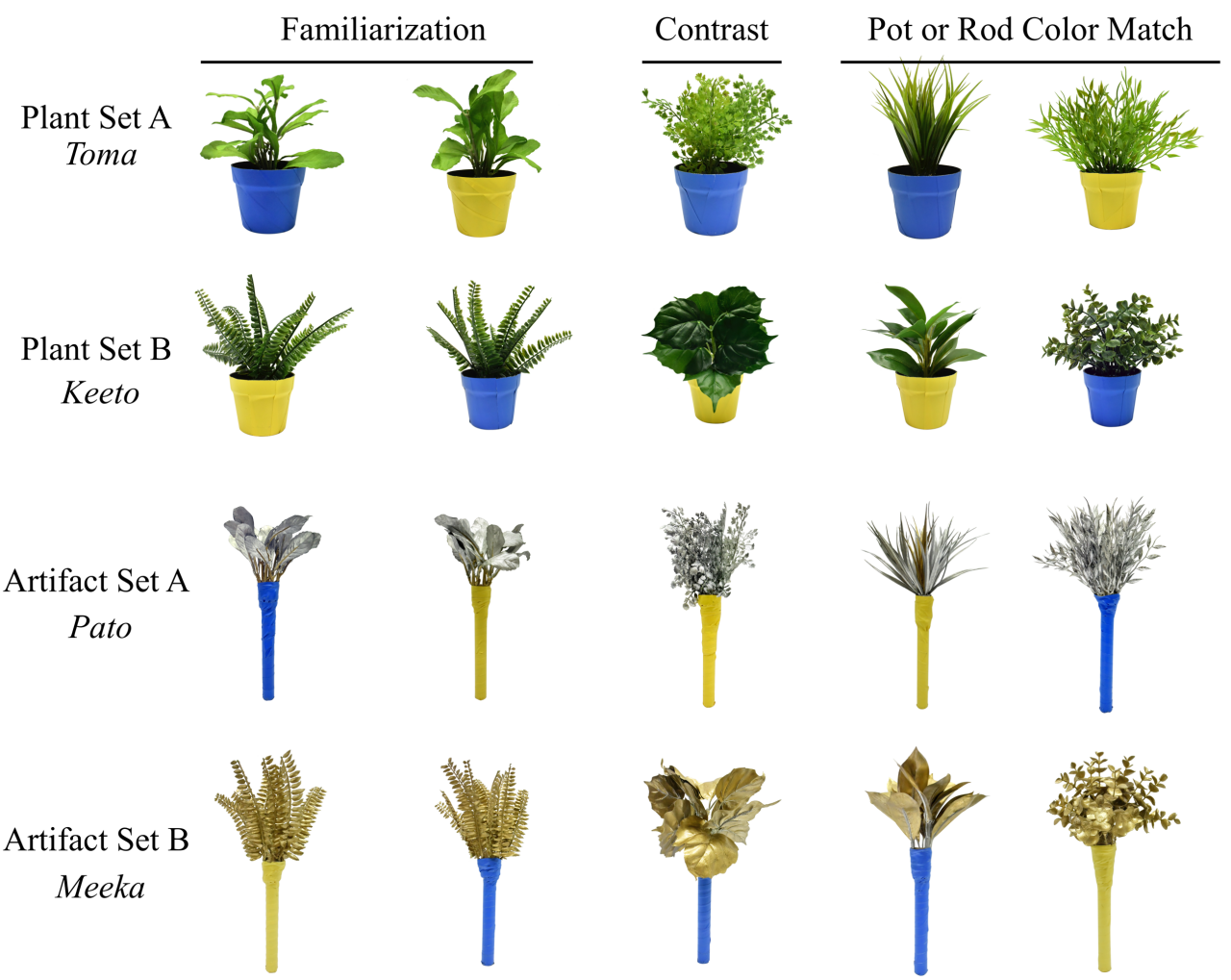

Fig. 1. The stimuli used in Study 1. Each trial featured all objects of either set A or B. First, the familiarization objects (that shared subtle shape cues) were presented during the familiarization phase. Then the contrast object (that differed in subtle shape cues from the familiarization objects) was presented during the contrast phase. Subsequently, two objects, one object from the familiarization phase and one pot / rod color match, were presented. Infants were asked to choose which one of these two test objects (pot / rod color match or subtle shape cue match) goes with the target, which was the remaining object from the familiarization phase. The objects' novel names were "toma", "keeto", "pato" and "meeka".

\subsubsection{Design and Procedure}

Infants were randomly assigned to one between-subjects condition (plant or artifact) after recruitment. Each condition featured two trials (one with all objects of set A and one with all objects of set B), which each had two choice phases. Thus, infants in each condition could provide data for up to four choice phases. Infants were seated on their parent's lap at a 
table across from the experimenter (E). Parents were asked to keep their eyes shut throughout the testing session so they would not inadvertently bias their infant's responses.

Familiarization phase. During the familiarization phase infants were presented with two objects that shared similar subtle shape cues and differed in their pot / rod color (see Fig. 2). E named the objects (in German) while pointing to them sequentially, and said: "Look, this is a toma and this is a toma" (note that we present the example of the "toma" stimulus set throughout; a different novel name was used for each trial). Then, the familiarization objects were placed in front of the infant so that they could explore them. E looked down at the table while infants explored the familiarization objects. After $15 \mathrm{~s}$, each familiarization object was named again. The familiarization objects were moved closer to $\mathrm{E}$ and were each named once more ("And don't forget, this is a toma and this is a toma."). In total, the familiarization objects' novel name was spoken six times.

Contrast phase. Next, E introduced a contrast object and indicated that it was not of the named category. E pointed to the contrast object and said: "Uh oh, this is not a toma" with a slightly concerned tone of voice (see Booth \& Waxman, 2002a). Then, the infant could explore the contrast object for $15 \mathrm{~s}$ while E looked down at the table. The contrast object was then removed. The contrast objects always differed from the familiarization objects in subtle shape cues, to demarcate the category boundary.

Choice phase. Following the contrast phase, the infant was presented with a pair of test objects: one was a subtle shape cue match, and the other was a pot / rod color match. The subtle shape cue match was one of the objects presented during the familiarization phase. The pot / rod color match was a novel object that always had a different pot / rod color than the subtle shape cue match. The test objects remained in front of the infant for $15 \mathrm{~s}$ so that infants could explore them. 
Next, the test objects were placed out of the infant's reach on E's side of the table, and the remaining familiarization object (hereafter the "target") was presented centrally in front of E (see Fig. 2). E pointed to the target and, once infants attended to the target object by looking at it, E said: "Remember, this one was a toma." Then, E asked: "Can you show me, which of these two (E points to the two test objects) goes with this one (E points to the target object)?" After saying “these two," E ensured that infants looked at both test objects by moving her index finger up and down above each test object (sequentially, starting on the right side). If infants did not look at both test objects, the pointing procedure was repeated. If infants did not attend to both test objects after several attempts to attract infants' attention by pointing, the question phrases were repeated (starting with “Remember, this one was a toma."). After pointing to each test object and ensuring that the infant had looked at both, E pointed to the target object again. Then, the test objects were placed in front of the infant so that they could indicate their choice by reaching for and touching one of the two test objects. If infants did not touch either test object, E repeated the question to show which test object goes with the target object (starting with "Remember this one was a toma") after $20 \mathrm{~s}$ and (if necessary) again after $40 \mathrm{~s}$. Once E observed a visually guided reach towards one of the test objects, or after $60 \mathrm{~s}$ elapsed without a touch towards a test object, E provided neutral feedback (E said, "Great job!" regardless of the infant's choice) and all objects were removed from the table. The next choice phase of the trial was presented with the remaining test objects from the same set (i.e., infants were again asked to indicate which of two test objects goes with a "toma" target object). Following the first trial, the second trial (with all objects of the remaining set, either A or B) commenced with the familiarization phase.

The novel names were chosen due to their phonetic similarity to real words in German, and based on prior work (Baldwin, 1991). The reason for re-presenting the familiarization objects as the subtle shape cue match during the choice phase, instead of 
presenting infants with entirely novel objects for each choice phase, was to decrease the demands on object memory and processing for the young age group of children in the current study. During the choice phase, E asked "Which one of these two goes with this one?" instead of "Which one of these two is a toma?", because infants had already seen the subtle shape cue match being referred to with the target object's name during the familiarization phase.

Therefore, we wanted to avoid infants merely matching the previously heard name to the test object it was previously presented alongside when selecting the subtle shape cue match (see Nazzi \& Gopnik, 2001). Additionally, while infants have been shown to take a longer time to touch plants compared to other object types (Elsner \& Wertz, 2019; Wertz \& Wynn, 2014a; Włodarczyk et al., 2018), infants’ reluctance to touch plants was likely not a relevant factor influencing their choices in this study. Infants here had up to 1 min to touch the objects, while studies of infants' reluctance to touch plants typically had 10 to $30 \mathrm{~s}$ time-out criteria. Further, across the plant and artifact conditions, an approximately equal number of choice phases were excluded from the analyses because infants failed to touch either one of the test objects (see Section S1.3.1).

Counterbalancing. We counterbalanced which stimulus set appeared on the first trial (set A or set B), as well as the order of the two choice phases. We also counterbalanced the placement of the objects during the familiarization phase and the subtle shape cue match during the choice phases (left vs. right). 


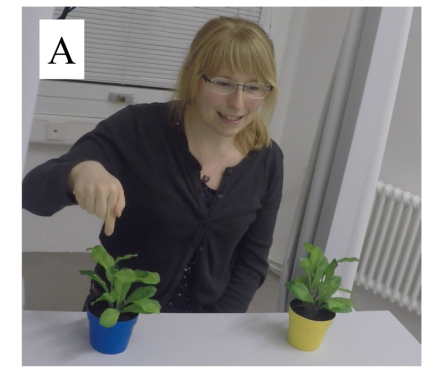

"Look, this is a toma, and this is a toma!"

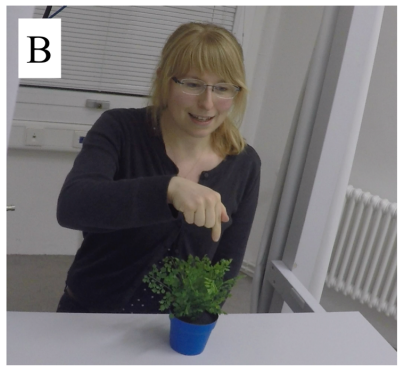

"Uh oh, this is not a toma."

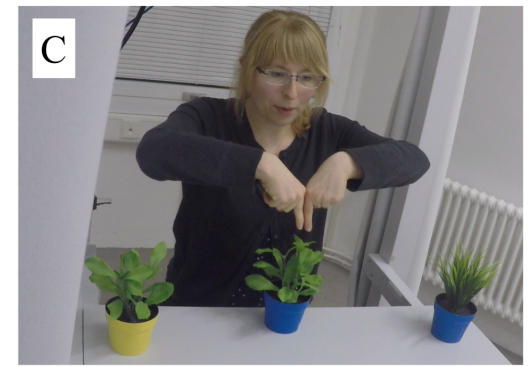

"Remember, this one was a toma."

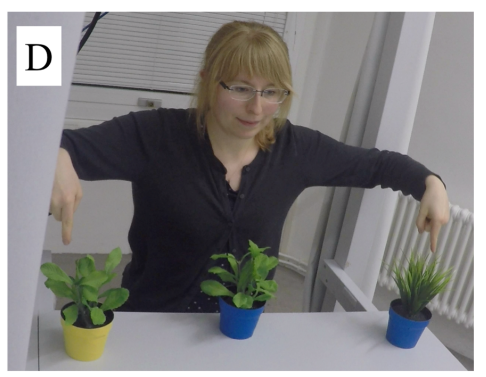

"Can you show me which one of these two..."

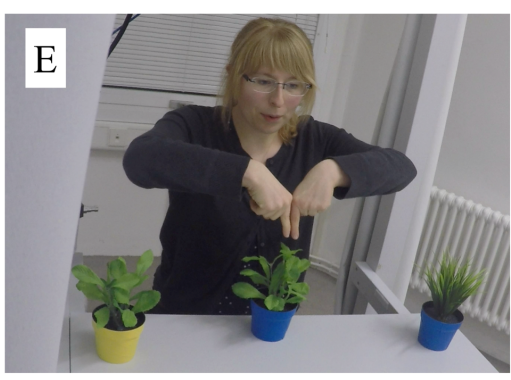

"..goes with this one?"

Fig. 2. An overview of key phases of the procedure. (A) Familiarization phase. Two

familiarization objects are presented and named, and infants are given $15 \mathrm{~s}$ to explore them.

(B) Contrast phase. Infants are presented with a contrast object that differs in subtle shape cues from the familiarization objects and given $15 \mathrm{~s}$ to explore it. (C-E) Choice phase. The target is presented centrally in front of $\mathrm{E}$ and two the two test objects are to her right (subtle shape cue match) and left (pot color match; the side of the test objects was counterbalanced across choice phases). Infants are asked which one of the test objects goes with the target.

\subsubsection{Parent Questionnaires}

To examine the role of experience with a category on infants' choices, parents completed the Plant Experience Questionnaire (Wertz \& Wynn, 2014a, 2014b), which assessed infant's prior plant-related experiences along 6 different items. For instance, parents were asked (in German) "How often do you name plants for your child?" and "How often does your child interact with plants?" Parents were asked to rate the frequency of prior experience with indoor and outdoor plants, and within the last month and the last summer months on 5-point Likert scales, with 1 indicating "never", 3 indicating "sometimes", and 5 
indicating "almost every day". In addition, parents filled out a vocabulary checklist in German (adapted from Szagun et al., 2009), ${ }^{1}$ asking for the number of words their infant says and understands.

\subsubsection{Coding and Analysis}

Infants' choices were scored by two independent coders (one coder, who was blind to the study hypotheses, and the first author) from videos of the test sessions. Coders determined whether infants showed a visually guided reach (i.e., the infant looks at, reaches towards and touches any part of an object during the choice phase) within $60 \mathrm{~s}$ (see also S1.3.1.). Choice phases on which infants did not choose either the subtle shape cue or pot / rod color match or their choice was ambiguous were excluded from further analyses. If the first two coders did not agree on a choice, a third coder either resolved the issue or, if all three coders did not agree, the choice was excluded from further analyses. Inter-rater agreement was as follows: Krippendorff's $\alpha=.90$.

In addition, to check whether subtle cues by E might have influenced infants' choices, a blind coder recorded the time (in s) E pointed to each of the objects (the subtle shape cue match and the pot / rod color match) during the choice phase. Videos of the experimenter were available for $N=37$ infants. One quarter of videos were scored by a second independent coder. Inter-rater agreement for this measure was as follows: $I C C=.95(r=.90)$.

Analyses were conducted in R (Version 3.6.1, R Core Team, 2018). Infants choices were scored as either $0=\operatorname{pot} /$ rod color match or $1=$ subtle shape cue match. As preregistered, we first analyzed infants' choices using a Generalized Linear Mixed Model with a binomial response term using the package lme4 (Bates et al., 2015). We included the factors condition (plant or artifact), gender and choice phase (1-4, z-transformed) as fixed effects, and included a random intercept for participant, a random intercept for stimulus set

\footnotetext{
${ }^{1}$ Two items were removed from the original vocabulary list, because they were deemed inappropriate.
} 
(Baayen, 2008) $)^{2}$, as well as a random slope for choice phase on participant and stimulus set. We note that the random effects components had a variance of zero or close to zero. This suggests that the model was likely overfitted with regards to its random effects. However, since the model converged and removing the random effects barely changed the estimates, we continued to explore this model. The significance of the predictors was tested using likelihood-ratio tests comparing the full model with a reduced model lacking the predictors of interest (Dobson, 2002).

Following Booth et al. (2005), we aggregated a proportion of subtle shape cue match choices out of all available choices (between 2 and 4) for each participant and compared it across conditions and to chance performance using Wilcoxon rank-sum tests, calculated with the package exactRankTests (Hothon \& Hornik, 2019). Moreover, to examine infants' choices at an individual level, we classified infants as subtle shape cue biased or not based on whether they chose the subtle shape match on more than $50 \%$ of choice phases or fewer than / exactly half of choice phases and compared the distribution of infants with these choice patterns using a Fisher's exact test. The time the experimenter pointed to the subtle shape cue match and the pot / rod color match were analyzed using paired-samples Wilcoxon signed rank tests within each condition.

\subsection{Results}

\subsubsection{Choices}

The GLMM predicting infants' choices for the subtle shape cue match indicated that the main effect of condition was significant, $\chi^{2}(1)=3.906, p=.048, \beta=0.681,95 \% \mathrm{CI}$ $[0.061,1.582]$ (see Fig. 3). There were no further effects of gender, $\chi^{2}(1)=0.002, p=.966$, or choice phase, $\chi^{2}(1)=2.239, p=.135$, on infants' choices (see Table S2).

\footnotetext{
${ }^{2}$ Stimulus set was included as a random instead of a fixed effect based on suggestions by Baayen (2008).
} 
Infants in the plant condition made more subtle shape cue match choices $(M=0.62$, $S D=0.19)$ than did infants in the artifact condition $(M=0.46, S D=0.15), W=290, p=.01$, $95 \%$ CI $[0.00,0.25]$. The proportion of subtle shape cue match choices was greater than chance in the plant condition, $V=66.5, p=.032,95 \%$ CI $[0.54,0.88]$, while the proportion of choices for the subtle shape cue match did not differ from chance in the artifact condition, $V=$ $17, p=.32,95 \%$ CI $[0.29,0.67]$.

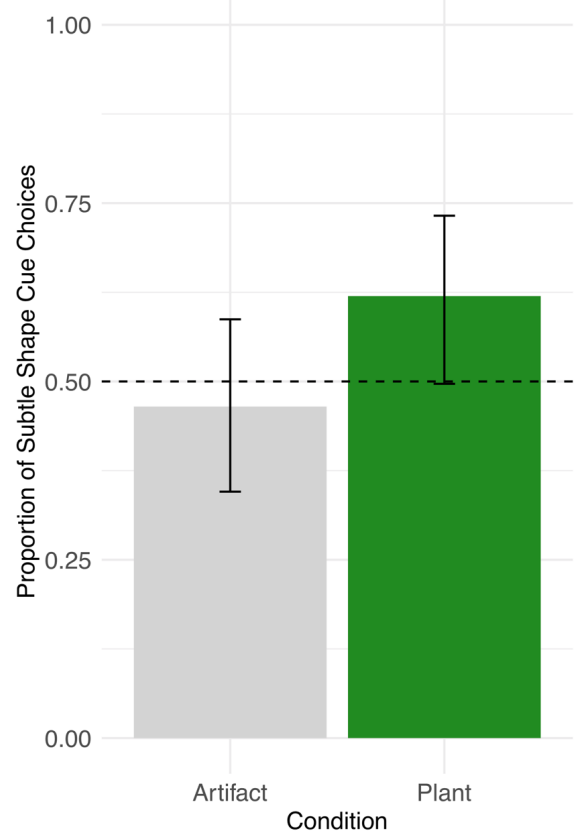

Fig. 3. The proportion of choices for the subtle shape cue match in the plant and artifact condition in Study 1. Bars show exact binomial 95\% Confidence Intervals.

A comparison of the number of infants who chose the subtle shape cue match at above chance level to the number of infants who showed no preference or chose the subtle shape cue match at below chance levels (see Table 1) indicated that the distributions of infants with these choice patterns differed across conditions, Fisher's exact test $[\mathrm{N}=40], p=.041$. That is, there were more subtle shape cue biased infants in the plant condition than in the artifact condition. However, many infants (18 out of 40) showed no distinct choice pattern and chose at chance levels throughout the study.

Table 1. 
The Number of Infants with each Choice Pattern by Condition in Study 1

\begin{tabular}{|c|c|c|}
\hline & \multicolumn{2}{|c|}{ Condition } \\
\hline & Plant & Artifact \\
\hline $\begin{array}{l}\text { More than } 50 \% \text { choices for } \\
\text { the subtle shape cue match }\end{array}$ & 10 & 3 \\
\hline Chance performance & 8 & 10 \\
\hline $\begin{array}{l}\text { Less than } 50 \% \text { choices for } \\
\text { the subtle shape cue match }\end{array}$ & 2 & 7 \\
\hline
\end{tabular}

\subsubsection{Questionnaires}

The proportion of subtle shape cue match choices showed no relation to infants' productive, $r_{\tau}=-0.2, p=.1$, or receptive vocabulary, $r_{\tau}=0.06, p=.62$, combined across both conditions. There was also no relation between infants' proportion of choices for the subtle shape cue match in the plant or artifact condition and infants' prior plant experience as assessed by the Plant Experience Questionnaire (Wertz \& Wynn, 2014a, 2014b) after adjusting for repeated testing by applying a Bonferroni-correction to the alpha-level $(\alpha=$ 0.0125; all $p \mathrm{~s}>.12$, see also Section S1.3.3.).

\subsubsection{Experimenter Effects}

The experimenter pointed an approximately equal amount of time to the subtle shape cue match $(M=1.38 \mathrm{~s}, S D=1.08 \mathrm{~s})$ and the pot color match $(M=1.34 \mathrm{~s}, S D=0.97 \mathrm{~s})$ during the choice phase in the plant condition, $T=32.5, p=.68,95 \%$ CI $[-1,1.5]$. Similarly, there was no clear difference in the amount of time that the experimenter spent pointing to either the subtle shape cue match $(M=1.24 \mathrm{~s}, S D=0.92 \mathrm{~s})$ or rod color match $(M=1.27 \mathrm{~s}, S D=$ $0.88 \mathrm{~s})$ in the artifact condition, $T=25, p=1,95 \% \mathrm{CI}[-2,1]$.

\subsection{Discussion of Study 1}


The findings of Study 1 suggest, in line with the predictions from the importance of distinguishing between different plant species (Oña et al., 2019) and a conceptual relevancebased account of early categorization (Booth et al., 2005), that 18-month-olds use different cues to categorize plants and artifacts. In particular, infants preferred subtle shape cues to categorize plants, while for artifacts infants used both subtle shape cues and rod color equally as a cue to categorization.

At the same time, the task infants were presented with was quite difficult, leading to many infants choosing at chance. Indeed, in a previous study, infants this age were prescreened for their ability to select objects with familiar names (Booth et al., 2005). We did not prescreen our participants in this way; thus, performance limitations might have masked larger differences in infants' strategies for plant and artifact categorization, which may have led to a rather small effect. In addition, it should be noted that despite the positive support for our hypothesis we found in Study 1, the effect was smaller than the effect we had .8 power to detect based on the sensitivity power analysis. Moreover, we had chosen to ask infants which one of the two test objects "goes with" the target (German: "dazu passen"). The reason for choosing this wording was that we re-presented one of the previously named familiarization objects as a test object during the choice phase (see Nazzi \& Gopnik, 2001). We thus wanted to ensure that infants did not merely match the novel name they had previously heard during the familiarization phase to the object that it had co-occourred with during the choice phase. Therefore, we did not ask infants "Which one is a toma" (e.g., Booth \& Waxman, 2002a). As a consequence of this decision, however, the wording of the question may have unintentionally been ambiguous as both objects to some extent "go with" the target.

Lastly, the difference between the plant and artifact conditions may have been small because shape cues are also relevant for categorizing many objects other than plants (e.g., artifacts and animals), and infants and young children rely on shape cues to categorize these 
kinds of objects to a large degree (Booth et al., 2005; Diesendruck \& Bloom, 2003; Landau et al., 1988; Smith et al., 1996). It is therefore not surprising that shape cues were also sometimes used to categorize our artifact stimuli. Nevertheless, Study 1 shows that shape can be handled differently when categorizing different kinds of objects. Specifically, consistent with our preregistered hypothesis, infants were more likely to rely on subtle shape cues for categorizing plants than for categorizing artifacts.

\section{Study 2}

In Study 2, we explored whether the differing categorization strategies for plants and artifacts we found in infants persist into adulthood. The problem of distinguishing between different plants was a critical part of adult life across evolutionary time (see e.g., Hardy \& Kubiak-Martens, 2016), although adults in Western, Educated, Industrialized, Rich and Democratic (WEIRD; Henrich et al., 2010) societies may only infrequently engage with plants in ways that require identifying distinct plant types. As a result, adult plant categorization strategies in the population we tested may not be representative of the categorization strategies that would be used by adults who regularly engage in subsistence practices that require close contact with the natural world (see e.g., Ross et al., 2003). Therefore, we are not attempting to make claims about the detailed function or structure of plant categorization strategies in adulthood. Instead, our goal in this study is to test for convergent evidence in adults of the strategies we uncovered in infancy.

Previous studies have looked at adults' ability to recognize plants from minimal cues (Cutting, 1982) and tested categorization strategies in tree experts (Medin et al., 1997), showing that adults use distinct categorization strategies for plants and plant-like objects. Here, we adapted the categorization task from Study 1 in order to directly compare adults' categorization strategies for plants and artifacts. If the categorization strategies we found in Study 1 persist into adulthood, we predicted that adults would weigh subtle shape cues more 
when categorizing plants than artifacts. We modified the procedure from Study 1 to be more appropriate for adult participants and suitable to be run online as data collection took place in the midst of an interruption of in-person data collection during the first wave of the Coronavirus-pandemic in Europe in the spring of 2020. In particular, in Study 2, instead of presenting two choice options simultaneously and asking participants to choose one that matches a target, we wanted to probe participants' willingness to accept two types of objects as category members separately: subtle shape cue matches and pot / rod color matches (see Booth et al., 2005; Booth \& Waxman, 2002b). This modification of the procedure of Study 1 was introduced because we expected that asking adults to choose directly between two objects in such a simple task could lead to little variation in response (i.e., potential ceiling effects).

Notably, adults (and older children) have been found to use conceptual relevance to guide their classification of objects, more so than young children (e.g., Keil, 1989). For instance, adults are more likely than young children to use function over perceptual similarity to categorize novel artifacts (Hammer \& Diesendruck, 2005). Similarly, adults tend to categorize natural kinds (e.g., animals) according to color, while they preferentially categorize machines according to size; overall similarity was a key feature of adults' categorization for both kinds of objects (Kelemen \& Bloom, 1994). While this body of work suggests that conceptual knowledge increasingly influences categorization throughout the lifespan, perceptual-associationist approaches emphasize the role of visual features, rather than objectspecific knowledge, in category formation throughout development (e.g., Rogers \& McClelland, 2005; see Smith, 2005 for a review). According to these approaches, conceptual knowledge continues to play a subordinate role in categorization beyond early childhood. Therefore, as in Study 1, Study 2 speaks to the question of whether adults use the same cues to categorize all kinds of objects (suggesting a general categorization rule), or whether adults 
use different cues for plant and artifact categorization (suggesting specific categorization rules).

\subsection{Methods}

\subsubsection{Ethical Approval}

This study was approved by the Ethics Committee of the Max Planck Institute for Human Development.

\subsubsection{Participants}

For Study 2 we recruited $N=150$ English-speaking adults via the online platform Prolific.ac. Participants were pre-screened based on their current location in the UK, US or Ireland, which comprises most of the account holders on Prolific.ac and were remunerated with 0.5 GBP. Data was excluded, if participants did not consent to the recording of their data $(N=1)$ or did not answer a screening item to detect careless responses correctly $(N=4)$. The final sample included $N=145$ adults $(N=100$ females, $N=43$ males, and $N=2$ who identified as neither gender). Participants' median age was $M=30$ (range: 18 to 78 ).

We recruited English- rather than German-speaking adults for Study 2, because Prolific.ac has a larger number of account holders from English-speaking countries than from Germany (fewer than 5\% of persons with Prolific.ac accounts are from Germany as of the $25^{\text {th }}$ of November 2020). As Study 2 was not designed to be identical to Study 1, we did not aim to recruit a German-speaking adult sample.

We expected a rather small effect based on Study 1 and because adults frequently use shape as a cue to categorization, although their reliance on cues to categorization tends to be more selective to the type of object being categorized than that of young children (e.g., Hammer \& Diesendruck, 2005; Kelemen \& Bloom, 1994). Therefore, we substantially increased the sample size from Study 1 to ensure adequate statistical power to detect small effects. An a priori power analysis conducted with the R-package simr (Green \& MacLeod, 
2016) estimated power of 1 - beta $=1[0.97,1]$ based on 1000 iterations to detect an effect of $\log$ odds $=1.85$ (or odds ratio $=6.36$; the smallest effect size we estimated to find based on pilot data), for the interaction of condition and object type with $N=150$ participants. A sensitivity power analysis conducted using the same approach indicated that with our final sample size of $N=145$, we had $1-$ beta $=1[0.97,1]$ power to detect an effect of the same magnitude as the effect of condition in Study 1.

\subsubsection{Design, Procedure and Stimuli}

Participants were randomly assigned to one between-subjects condition (plant or artifact). In each trial a target object was presented with that objects' name (e.g., "This is a toma."). Then, adults were presented with one of two types of objects: either a subtle shape cue match or pot / rod color match (within-subjects factor). In total, participants provided category acceptance judgements for 12 items per condition, split into two sets (set A and B) of six items each (see Fig. 4). Each set consisted of one target object, three subtle shape cue match objects, and three pot / rod color match objects. Randomization was accomplished at two levels: participants either saw set A or set B first (counterbalanced across participants), and all items within each set were presented in a fully randomized order.

After they provided informed consent, a screening item to detect careless responses was presented to participants (Oppenheimer et al., 2009). Then adults were asked whether a pot / rod color match or subtle shape cue match had the same name as a target ("Is one also a toma? (Select a response to indicate your choice.)") with the response options "yes" or "no". This question was not identical to the question in Study 1, where infants were asked which object, a subtle shape cue match or a pot / rod color match, "goes with" the target. The reason for this change is, as we noted above, that the wording of Study 1 was rather ambiguous, as both the pot / rod color match and the subtle shape cue match could to some extent "go with" the target. We therefore chose a wording that may tap into categorization mechanisms more 
directly by asking adults whether the subtle shape cue and the pot / rod color match share the same name (a count noun) with the target (e.g., Booth et al., 2005; Booth \& Waxman, 2002a; 2002b; Hammer \& Diesendruck, 2005; Kemler Nelson et al., 2000; Markman, 1989). The names of the target objects were the same novel names used in Study 1, which parallels previous work on adults' categorization (Hammer \& Diesendruck, 2005).

After completing the categorization task, participants were asked whether they were familiar with the specific objects, and whether they were familiar with any of the specific object names presented to them prior to their participation. Slightly more adults indicated that they were previously familiar with the specific plants (10 out of 73$)$ than artifacts (3 out of 72), but the difference was only marginally significant, Fisher's exact test $(\mathrm{N}=145), p=.078$. Participants were equally unfamiliar with the objects' novel names across conditions. Only one participant per condition indicated that they were familiar with the objects' names before completing the study, Fisher's exact test $(\mathrm{N}=145), p=1$.

The stimuli were created by digitally modifying the pot / rod colors of the stimuli used in Study 1. Across all stimuli the sub-part (the leafy part) of the subtle shape cue match slightly differed in configuration from that of the target object, as was the case in Study 1. 


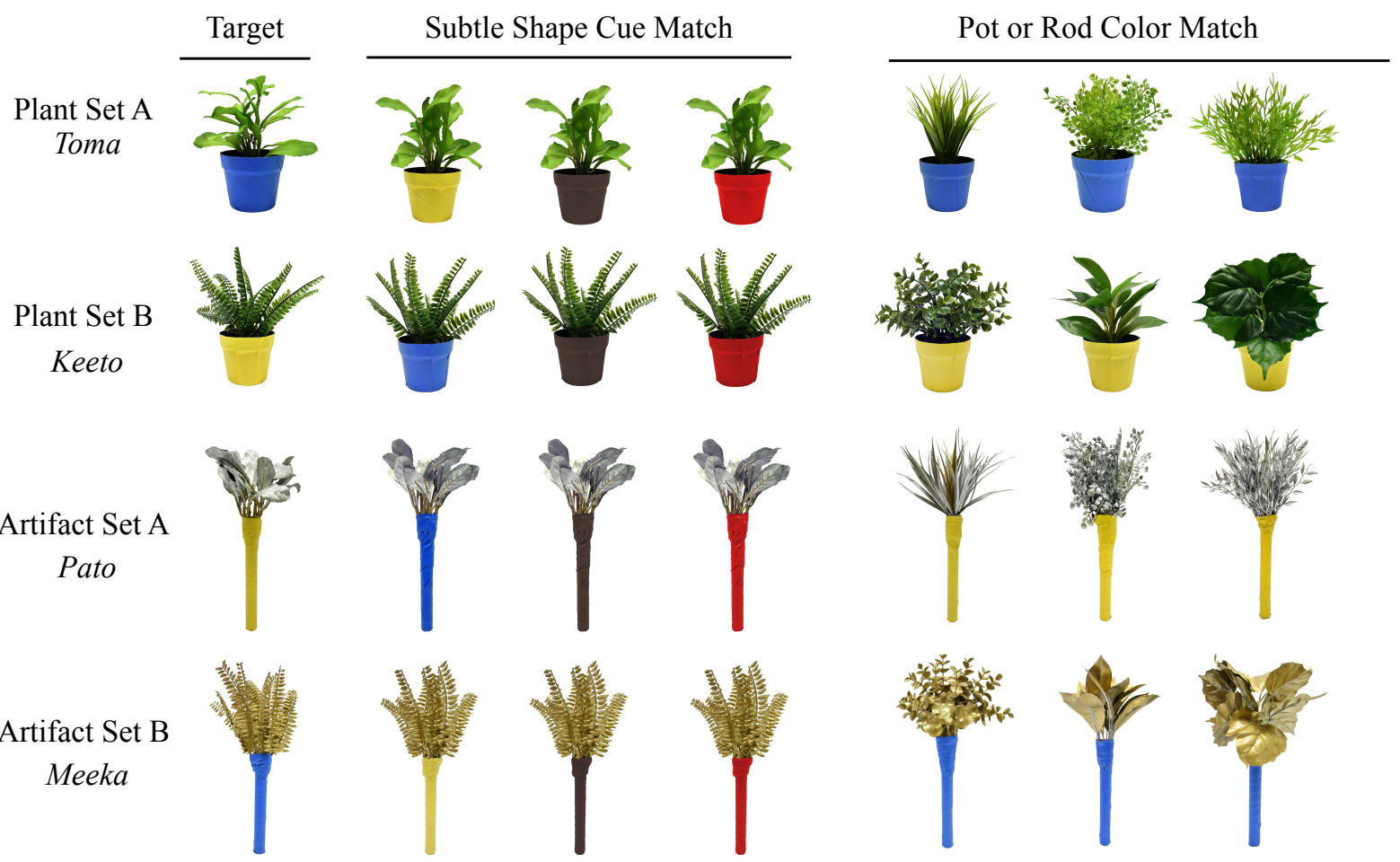

Fig. 4. An overview of the stimuli used in Study 2. Participants viewed one object set (A or B), followed by the other. In each trial, participants were presented with the target object and its name (e.g., "This is a toma"). Participants were then shown either a subtle shape cue match or a pot / rod color match and asked whether it shared the target objects' name (e.g., "Is this one also a toma? (Select a response to indicate your choice.)"). The response options were “yes" or "no".

\subsubsection{Analysis and Results}

As in Study 1, we used Generalized Linear Mixed Models with a binomial response term to analyze participants' category acceptances. Participants responses were scored as either accept (= 1 or "yes") or reject (= 0 or "no"). The models were fitted with the package lme4 (Bates et al., 2015) in R. The model included the interaction of condition and object type, trial number (1-12, z-transformed), gender, as well as age (z-transformed). As in Study 1, we included a random intercept of stimulus set and participant, as well as a random slope for trial on participant, and on stimulus set. The significance of the predictors was tested using 
likelihood-ratio tests comparing model fit between a model with the predictor and one lacking it (Dobson, 2002).

Providing support for our main prediction, adults' category acceptance varied significantly as a function of the interaction of condition and object type, $\chi^{2}(1)=24.518, p<$ $.001, \beta=3.474,95 \%$ CI $[1.769,4.721]$ (see Fig. 5). On average, participants were almost equally likely to accept the subtle shape cue match in both the plant $(M=0.95)$, and artifact condition $(M=0.92)$. On the other hand, adults were less likely to accept the pot color match in the plant condition $(M=0.05)$ than they were to accept the rod color match in the artifact condition $(M=0.14)$. The effects of age, $\chi^{2}(1)=0.865, p=.352$, gender, $\chi^{2}(2)=0.152, p=$ .927 , and trial, $\chi^{2}(1)=3.019, p=.082$, were not clearly relevant in predicting adults' category acceptances (see Table S7).

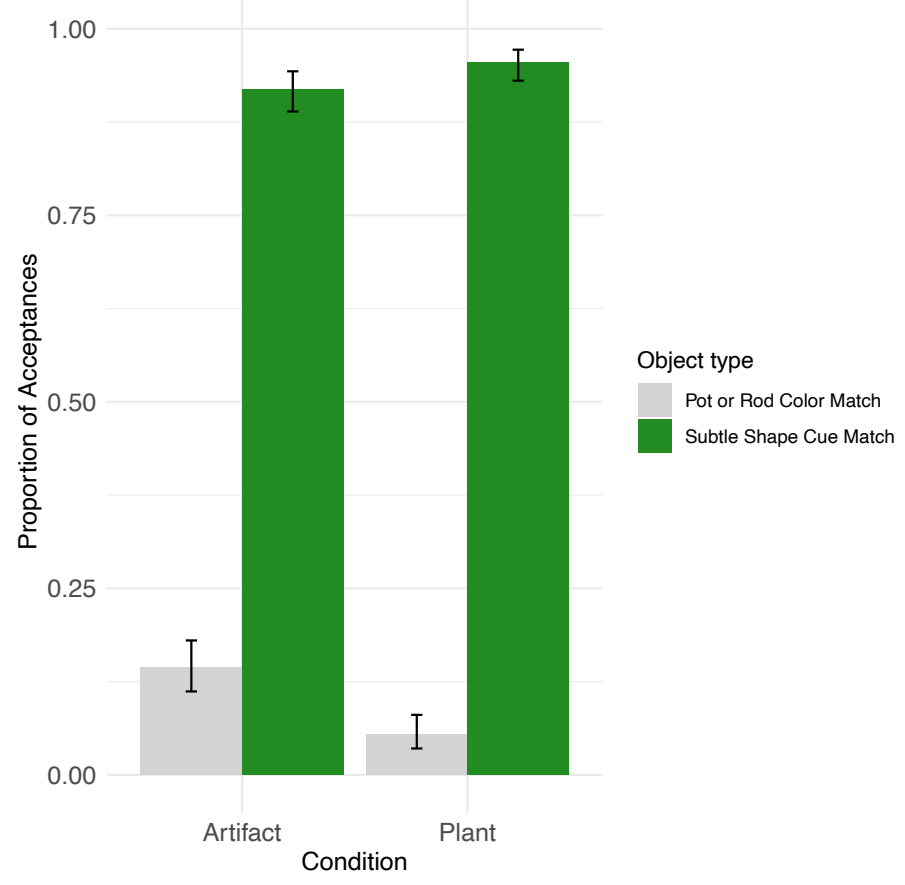

Fig. 5. The proportion of "yes" responses to the question "Is this one also a [target object name]?" in Study 2. Error bars show exact binomial 95\% Confidence Intervals.

An additional exploratory analysis showed that there was also a three-way interaction of condition, object type and trial, $\chi^{2}(1)=7.819, p=.005, \beta=2.145,95 \%$ CI $[0.425,4.042]$. 
Fig. S4 illustrates the three-way interaction. Importantly, on the first trial, participants were already less likely to accept the pot color match in the plant condition $(M=0.25)$ than the rod color match in the artifact condition $(M=0.41)$. Yet, with increasing trial number, adults' category acceptance of the pot / rod color match decreased in both conditions.

\subsubsection{Discussion of Study 2}

In Study 2 we found evidence that the different categorization strategies for plants and artifacts shown by infants in Study 1 persist into adulthood. In particular, across conditions, although adults relied heavily on subtle shape cues for both object types, they were significantly less willing to categorize plants by pot color than artifacts by rod color. In addition to the predicted effect, we also found that trial moderated the interaction of condition and object type, such that participants' willingness to accept pot / rod color matches gradually decreased over repeated trials. The influence of trial, however, cannot account for the main result regarding a lower level of acceptance of pot / rod color cues to categorize plants than artifacts. This difference was already apparent on the first trial and remained throughout the subsequent trials. Taken together, these results suggest that adults rely on subtle shape cues to categorize plants but are willing to accept dimensions other than subtle shape cues (in this case rod color) to categorize artifacts.

\section{General Discussion}

Humans, like countless other species, have relied on plants for millennia. Interactions between plants and herbivores have resulted in the co-evolution of a myriad of plant defense mechanisms and corresponding physiological and behavioral adaptations in the species that feed on them (e.g., Freeland \& Janzen, 1974; Fürstenberg-Hägg et al., 2013; Knolhoff \& Heckel, 2014; Perry, 2011; Placek et al., 2017; Rioux, 2019). Building on recent work, which has begun to uncover cognitive mechanisms that appear to function to mitigate harmful consequences of plant-human interactions (the Plant Learning and Avoiding Natural Toxins, 
or PLANT, systems; see Wertz, 2019 for a review), here, we examined which features infants use to categorize plants and artifacts. The results of Study 1 show that 18 -month-olds use subtle leaf shape cues to categorize plants and rely less on similar cues for shape-matched artifacts. Moreover, in a modified version of the categorization task in Study 2, adults also relied on subtle shape cues for plant categorization while showing a greater willingness to categorize artifacts according to other features (i.e., rod color), suggesting that the differing categorization strategies we observed in infancy persist into adulthood.

Previous work had shown that 18-month-olds distinguish between plants with different leaf shapes and fruit colors (Wertz \& Wynn, 2019). Because the authors were pursuing a different research question only plant stimuli were used in these studies. Therefore, one explanation for these earlier results might be that infants relied on the perceptual differences alone to categorize the stimulus plants and would have favored distinguishing between all types of objects based on the same variance in subtle shape cues (leaf shape) and fruit color. If this were true, we would have expected infants to rely on subtle shape cues to categorize both the plant and artifact stimuli in Study 1. The results of Study 1, however, suggest that infants rely on subtle shape cues more when categorizing plants than when categorizing artifacts. These results are consistent with the implications of recent modeling work on plant social learning that highlights the necessity of correctly distinguishing between plant types that may look quite similar to one another (Oña et al., 2019).

The results of Study 1 are also consistent with an account of early conceptual development that proposes that infants' and young children's categorization is informed by the conceptual relevance of features to the kind of object being categorized (Booth et al., 2005; Booth \& Waxman, 2002b; Kemler Nelson et al., 2000; Lavin \& Hall, 2001; Macario, 1991). While much of this work has examined categorization abilities in older toddlers and preschoolers, the present findings accord with research showing that infants are capable of 
making fine-grained distinctions within superordinate categories, such as between two types of vehicles or different species of dogs (Mandler \& McDonough, 2000; McDonough \& Mandler, 1998; Saffran et al., 2007), beyond distinguishing between global categories, such as plants, animals and vehicles (Mandler et al., 1991; Mandler \& McDonough, 1993; McDonough \& Mandler, 1998; Pauen, 2002). Moreover, conceptual representations of objects such as animals, artifacts and plants may also be present at an earlier age. For instance, evidence from looking-time studies has revealed that infants are sensitive to the features that distinguish animate from inanimate entities by 6 months of age (e.g., Johnson, 2003; Spelke et al., 1995; Woodward, 1998), and that infants by 8 months hold expectations regarding the biological properties of animals (Setoh et al., 2013). Moreover, reaching studies reveal selective responses to plants by the same age (Elsner \& Wertz, 2019; Wertz \& Wynn, 2014a; Włodarczyk et al., 2018, 2020). Thus, examining whether infants are sensitive to the conceptual properties of plants in categorization tasks at a younger age than suggested by Study 1 may be a fruitful avenue for future research. At the same time, the explicit task employed in this study was quite challenging for this age group of children (see also Booth et al., 2005). Hence using methods that are less taxing for infants may be promising in this regard. To be clear, infants' early conceptual "knowledge" of plants is likely to be implicitly represented, while more explicit knowledge regarding the specific features of artifacts, and plants, and behavior of animals continues to develop throughout early and middle childhood (e.g., S. A. Gelman, 1988; Greif et al., 2006; Keil, 1989).

Moreover, in Study 1, we found no evidence to suggest that infants with larger vocabularies generally attend to shape when categorizing objects in naming contexts (e.g., Jones \& Smith, 2002; Jones, Smith, \& Landau, 1991; Landau et al., 1988; Smith et al., 1996). The absence of a relationship between infants' vocabulary and categorization abilities (or specifically, attendance to shape for categorization) accords with previous studies (Booth et 
al., 2005), which have supported the view that infants' categorization is not defined by a single rule such as "attend to shape in a naming context". Rather these studies suggest that infants' and young children's categorization is motivated by the conceptual relevance of features, such as shape (Booth et al., 2005; Diesendruck \& Bloom, 2003), texture (Booth et al., 2005; Booth \& Waxman, 2002b), or function (Diesendruck et al., 2003; Kemler Nelson et al., 2000; Truxaw et al., 2006) for categorization, while the specific weight of each of these features for categorization is determined by the object kind (see also Diesendruck \& Peretz, 2013).

The results of Study 2 show that adults retain aspects of the different categorization strategies for plants and artifacts we found in infancy. This is in line with the view that conceptual knowledge is relevant to categorization in adulthood (e.g., Hammer \& Diesendruck, 2005; Kelemen \& Bloom, 1994). Notably, the results of Study 1 and Study 2 are unlikely to have been caused by unintended perceptual differences in our stimuli because adults' ratings of the visual similarity of plants and artifacts did not significantly differ (see Study 1a, Section S2 in the Supplementary Materials). The results of Study 2 are consistent with studies of neurally-impaired patients showing category-specific deficits for processing information about plants, foods, animals and artifacts (Caramazza \& Shelton, 1998; Hillis \& Caramazza, 1991; Mahon \& Caramazza, 2011; Ralph et al., 1998; Rumiati \& Foroni, 2016). Importantly, these studies of category-specific deficits suggest that plants are not necessarily treated as just another type of living thing, similar to animals (see Caramazza \& Shelton, 1998 for a review). Indeed, several studies show that the naming of animals and plants (or fruits and vegetables) can be selectively impaired (or spared from impairment; Hart et al., 1985; Hart \& Gordon, 1992; Hillis \& Caramazza, 1991). Taken together, these results support the view that the human mind contains a collection of evolved systems for processing information about different kinds of ancestrally-relevant content. Some of these evolved systems may 
provide a basis, in the form of content-specific learning rules, for the acquisition of categoryspecific knowledge early in development (see e.g., Barrett et al., 2016; Barrett \& Broesch, 2012; Broesch et al., 2014; DeLoache \& Lobue, 2009; LoBue et al., 2010; Wertz, 2019).

It is important to note that infants' and adults' reliance on subtle shape cues to categorize plants still, of course, requires them to use perceptual similarities between objects. Similarly, infants' and young children's selective reliance on texture to categorize animals (Booth et al., 2005), and function to categorize artifacts (Kemler Nelson et al., 2000) necessarily requires perceptual processes. Therefore, we do not intend to claim that using conceptually relevant features is somehow divorced from perceptual processing. Instead, we conclude that the conceptual relevance of object properties is instrumental in infants' categorization of plants to the degree that these perceptual features (in this case subtle shape cues) are handled differently when categorizing plants and artifacts.

\subsection{Limitations}

One limitation of the current work is that the artifacts may have been relatively more novel to the infants than the plants. Infants may have been more familiar with plants, even if they had never seen the particular plant exemplars we used. A lack of familiarity with objects can be a reason that young children rely on perceptual similarity (e.g., in shape) over other potentially relevant features for categorization (Cimpian \& Markman, 2005). While it would be relevant for future work to examine infants' reliance on subtle shape cues with more familiar artifacts, there is evidence that infants this age nevertheless are capable of using object parts in both more and less novel configurations to categorize objects (Rakison \& Butterworth, 1998). Therefore, we favor the interpretation that infants did not prefer to use subtle shape cues to categorize artifacts because they were construed as conceptually less relevant to distinguish between artifact than plant types. 
In addition, our study was not directly designed to address the role of individual differences in prior experience on infants' categorization of plants, however, we still wanted to examine the role experience might play through parental questionnaires. We did not find a clear relation between infants' prior plant experiences and reliance on subtle shape cues to categorize plants. Nonetheless, it seems likely that experience would be instrumental in infants' reliance on conceptually relevant cues for categorization (see Jones \& Smith, 2002, Study 3; Hurley \& Oakes, 2015; Kovack-Lesh et al., 2014). It would be an interesting avenue for future work to examine more directly how early experiences with plants influence children's attentional strategies (e.g., attention to subtle shape cues), and their early concept formation about plants.

Finally, as noted by an anonymous reviewer, we might have expected to see stronger effects in our infant study (Study 1) given the importance of distinguishing between different types of plants over evolutionary time. We discuss three reasons why we may not have observed a larger effect. These reasons are not mutually-exclusive and may all contribute to some degree. The first reason may be our participant population. Testing infants is inherently noisy, and it is typically the case that there is variability in their responses due to performance factors like limited attention span and/or memory (e.g., Ross-Sheehy et al., 2003). Relatedly, the underlying fine-grained plant categorization mechanisms we tested in Study 1 may still be immature at 18 months of age. Second, it may be that our naming task did not engage the fine-grained categorization mechanisms to the same degree that other content might. For example, previous studies of 18-month-olds' plant categorization using edibility information found more robust effects (Wertz \& Wynn, 2019). It may be less costly to categorize a plant incorrectly than to eat off of the wrong plant. Lastly, in contrast to the study of Wertz \& Wynn (2019), here, we pitted two potential categorization cues - subtle shape cues and pot color-against each other. Therefore, it may be that a modest effect size emerged for plant 
categorization because it is still quite challenging for infants of this age to override the pull to categorize objects by a visually salient cue (the brightly colored pots), despite their emerging ability to use conceptually relevant knowledge. In line with this view, the results of Study 2 show near perfect performance for adults' ability to use conceptually relevant rather than (only) visually salient cues for plants. Future studies can interrogate these proposals by testing older infants, presenting different types information about plants, and using different competing cues.

\subsection{Conclusion}

Infants rely on subtle shape cues (leaf shape) to categorize plants more than to categorize artifacts. As indicated by Study 2, these different categorization strategies persist to some extent into adulthood. We argue that infants' reliance on subtle shape cues to categorize plants may be rooted in early conceptual knowledge regarding which features are relevant to identifying plant types. Such implicit knowledge may have its origin in the functional importance of distinguishing between potentially dangerous plant types in ancestral environments.

\section{Open Practices}

Study 1 was preregistered. The data and analysis scripts for studies $1,1 \mathrm{a}$ and 2, and the stimulus images for studies 1a and 2 are available through the Open Science Framework: https://osf.io/5knxr/?view_only=ec1d247f3174446b8fa2b1be2e985722. 


\section{References}

Baayen, R. H. (2008). Analyzing linguistic data: a practical introduction to statistics using $R$. Cambridge University Press. https://doi.org/10.1017/CBO9780511801686

Baldwin, D. A. (1991). Infants' contribution to the achievement of joint reference. Child Development, 62(5), 875-890. https://doi.org/10.2307/1131140

Barrett, H. C., \& Broesch, J. (2012). Prepared social learning about dangerous animals in children. Evolution and Human Behavior, 33(5), 499-508. https://doi.org/10.1016/j.evolhumbehav.2012.01.003

Barrett, H. C., Peterson, C. D., \& Frankenhuis, W. E. (2016). Mapping the cultural learnability landscape of danger. Child Development, 87(3), 770-781. https://doi.org/10.1111/cdev.12495

Bates, D., Mächler, M., Bolker, B., \& Walker, S. (2015). Fitting linear mixed-effects models using lme4. Journal of Statistical Software, 67(1), 1-48. https://doi.org/10.18637/jss.v067.i01

Booth, A. E., \& Waxman, S. (2002a). Object names and object functions serve as cues to categories for infants. Developmental Psychology, 38(6), 948-957. https://doi.org/10.1037/0012-1649.38.6.948

Booth, A. E., \& Waxman, S. R. (2002b). Word learning is 'smart': evidence that conceptual information affects preschoolers' extension of novel words. Cognition, 84(1), B11B22. https://doi.org/10.1016/S0010-0277(02)00015-X

Booth, A. E., Waxman, S. R., \& Huang, Y. T. (2005). Conceptual information permeates word learning in infancy. Developmental Psychology, 41(3), 491-505. https://doi.org/10.1037/0012-1649.41.3.491

Broesch, J., Barrett, H. C., \& Henrich, J. (2014). Adaptive content biases in learning about animals across the life course. Human Nature, 25(2), 181-199. https://doi.org/10.1007/s12110-014-9196-1 
Caramazza, A., \& Shelton, J. R. (1998). Domain-specific knowledge systems in the brain: the animate-inanimate distinction. Journal of Cognitive Neuroscience, 10(1), 1-34. https://doi.org/10.1162/089892998563752

Cashdan, E. (1994). A sensitive period for learning about food. Human Nature, 5(3), 279291. https://doi.org/10.1007/BF02692155

Cashdan, E. (1998). Adaptiveness of food learning and food aversions in children. Social Science Information, 37(4), 613-632. https://doi.org/10.1177/053901898037004003

Chen, H., Cohen, P., \& Chen, S. (2010). How big is a big odds ratio? Interpreting the magnitudes of odds ratios in epidemiological studies. Communications in Statistics Simulation and Computation, 39(4), 860-864. https://doi.org/10.1080/03610911003650383

Chen, M.-S. (2008). Inducible direct plant defense against insect herbivores: A review. Insect Science, 15(2), 101-114. https://doi.org/10.1111/j.1744-7917.2008.00190.x

Cimpian, A., \& Markman, E. M. (2005). The absence of a shape bias in children's word learning. Developmental Psychology, 41(6), 1003-1019. https://doi.org/10.1037/00121649.41.6.1003

Cutting, J. E. (1982). Blowing in the wind: perceiving structure in trees and bushes. Cognition, 12(1), 25-44. https://doi.org/10.1016/0010-0277(82)90028-2

DeLoache, J. S., \& Lobue, V. (2009). The narrow fellow in the grass: Human infants associate snakes and fear. Developmental Science, 12(1), 201-207. https://doi.org/10.1111/j.1467-7687.2008.00753.x

Diesendruck, G., \& Bloom, P. (2003). How specific is the shape bias? Child Development, 74(1), 168-178. https://doi.org/10.1111/1467-8624.00528

Diesendruck, G., Markson, L., \& Bloom, P. (2003). Children's reliance on creator's intent in extending names for artifacts. Psychological Science, 14(2), 164-168. 
https://doi.org/10.1111/1467-9280.t01-1-01436

Diesendruck, G., \& Peretz, S. (2013). Domain differences in the weights of perceptual and conceptual information in children's categorization. Developmental Psychology, 49(12), 2383-2395. https://doi.org/10.1037/a0032049

Dobson, A. J. (2002). An introduction to generalized linear models (2nd ed). Chapman \& Hall/CRC.

Dovey, T. M., Staples, P. A., Gibson, E. L., \& Halford, J. C. G. (2008). Food neophobia and 'picky/fussy' eating in children: A review. Appetite, 50(2), 181-193. https://doi.org/10.1016/j.appet.2007.09.009

Elsner, C., \& Wertz, A. E. (2019). The seeds of social learning: Infants exhibit more social looking for plants than other object types. Cognition, 183, 244-255.

Freeland, W. J., \& Janzen, D. H. (1974). Strategies in herbivory by mammals: the role of plant secondary compounds. The American Naturalist, 108(961), 269-289.

Fürstenberg-Hägg, J., Zagrobelny, M., \& Bak, S. (2013). Plant defense against insect herbivores. International Journal of Molecular Sciences, 14(5), 10242-10297. https://doi.org/10.3390/ijms140510242

Gelman, R. (1990). First principles organize attention to and learning about relevant data: number and the animate-inanimate distinction as examples. Cognitive Science, 14(1), 79-106. https://doi.org/10.1207/s15516709cog1401_5

Gelman, S. A. (1988). The development of induction within natural kind and artifact categories. Cognitive Psychology, 20(1), 65-95. https://doi.org/10.1016/00100285(88)90025-4

Gelman, S. A., \& Markman, E. M. (1986). Categories and induction in young children. Cognition, 23(3), 183-209. https://doi.org/10.1016/0010-0277(86)90034-X

Graham, S. A., Kilbreath, C. S., \& Welder, A. N. (2004). Thirteen-month-olds rely on shared 
labels and shape similarity for inductive inferences. Child Development, 75(2), 409427. https://doi.org/10.1111/j.1467-8624.2004.00683.x

Green, P., \& MacLeod, C. J. (2016). SIMR: An R package for power analysis of generalized linear mixed models by simulation. Methods in Ecology and Evolution, 7(4), 493-498. https://doi.org/10.1111/2041-210X.12504

Greif, M. L., Kemler Nelson, D. G., Keil, F. C., \& Gutierrez, F. (2006). What do children want to know about animals and artifacts? Psychological Science, 17(6), 455-459. https://doi.org/10.1111/j.1467-9280.2006.01727.x

Hagen, E. H., Sullivan, R. J., Schmidt, R., Morris, G., Kempter, R., \& Hammerstein, P. (2009). Ecology and neurobiology of toxin avoidance and the paradox of drug reward. Neuroscience, 160(1), 69-84. https://doi.org/10.1016/j.neuroscience.2009.01.077

Hammer, R., \& Diesendruck, G. (2005). The role of dimensional distinctiveness in children's and adults' artifact categorization. Psychological Science, 16(2), 137-144. https://doi.org/10.1111/j.0956-7976.2005.00794.x

Hardy, K., \& Kubiak-Martens, L. (2016). Wild harvest: plants in the hominin and preagrarian human worlds. Oxbow Books.

Hart, J., Berndt, R. S., \& Caramazza, A. (1985). Category-specific naming deficit following cerebral infarction. Nature, 316(6027), 439-440. https://doi.org/10.1038/316439a0

Hart, J., \& Gordon, B. (1992). Neural subsystems for object knowledge. Nature, 359(6390), 60-64. https://doi.org/10.1038/359060a0

Hothorn, T \& Hornik, K. (2019), exactRankTests: Exact distributions for rank and permutation tests. R package version 0.8-31.

Henrich, J., Heine, S. J., \& Norenzayan, A. (2010). The weirdest people in the world? Behavioral and Brain Sciences, 33(2-3), 61-83. 
https://doi.org/10.1017/S0140525X0999152X

Hillis, A. E., \& Caramazza, A. (1991). Category-specific naming and comprehension impairment: A double dissociation. Brain: A Journal of Neurology, 114 ( Pt 5), 20812094. https://doi.org/10.1093/brain/114.5.2081

Hurley, K. B., \& Oakes, L. M. (2015). Experience and distribution of attention: pet exposure and infants' scanning of animal images. Journal of Cognition and Development, 16(1), 11-30. https://doi.org/10.1080/15248372.2013.833922

Johnson, S. C. (2003). Detecting agents. Philosophical Transactions of the Royal Society B: Biological Sciences, 358(1431), 549-559. https://doi.org/10.1098/rstb.2002.1237

Jones, S., \& Smith, L. B. (2002). How children know the relevant properties for generalizing object names. Developmental Science, 5(2), 219-232. https://doi.org/10.1111/14677687.00224

Jones, S., Smith, L. B., \& Landau, B. (1991). Object properties and knowledge in early lexical learning. Child Development, 62(3), 499-516.

Keil, F. C. (1989). Concepts, kinds, and cognitive development. The MIT Press.

Kelemen, D., \& Bloom, P. (1994). Domain-specific knowledge in simple categorization tasks. Psychonomic Bulletin \& Review, 1(3), 390-395. https://doi.org/10.3758/BF03213980

Kemler Nelson, D. G., Russell, R., Duke, N., \& Jones, K. (2000). Two-year-olds will name artifacts by their functions. Child Development, 71(5), 1271-1288.

Kingsbury, J. M. (1983). The evolutionary and ecological significance of plant toxins. In R. F. Keeler \& A. T. Tu (Eds.), Handbook of natural toxins: plant and fungal toxins: Vol. Vol. 1 (pp. 675-706). Marcel Dekker Inc.

Knolhoff, L. M., \& Heckel, D. G. (2014). Behavioral assays for studies of host plant choice and Adaptation in Herbivorous Insects. Annual Review of Entomology, 59(1), 263278. https://doi.org/10.1146/annurev-ento-011613-161945 
Kovack-Lesh, K. A., McMurray, B., \& Oakes, L. M. (2014). Four-month-old infants’ visual investigation of cats and dogs: relations with pet experience and attentional strategy. Developmental Psychology, 50(2), 402-413. https://doi.org/10.1037/a0033195

Landau, B., Smith, L. B., \& Jones, S. (1988). The importance of shape in early lexical learning. Cognitive Development, 3(3), 299-321. https://doi.org/10.1016/08852014(88)90014-7

Lavin, T. A., \& Hall, D. G. (2001). Domain effects in lexical development: learning words for foods and toys. Cognitive Development, 16(4), 929-950. https://doi.org/10.1016/S0885-2014(02)00070-9

LoBue, V., Rakison, D. H., \& DeLoache, J. S. (2010). Threat perception across the life span: evidence for multiple converging pathways. Current Directions in Psychological Science, 19(6), 375-379. https://doi.org/10.1177/0963721410388801

Macario, J. F. (1991). Young children's use of color in classification: foods and canonically colored objects. Cognitive Development, 6(1), 17-46. https://doi.org/10.1016/08852014(91)90004-W

Mahon, B. Z., \& Caramazza, A. (2011). What drives the organization of object knowledge in the brain? Trends in Cognitive Sciences, 15(3), 97-103. https://doi.org/10.1016/j.tics.2011.01.004

Mandler, J. M., Bauer, P. J., \& McDonough, L. (1991). Separating the sheep from the goats: differentiating global categories. Cognitive Psychology, 23(2), 263-298. https://doi.org/10.1016/0010-0285(91)90011-C

Mandler, J. M., \& McDonough, L. (1993). Concept formation in infancy. Cognitive Development, 8(3), 291-318. https://doi.org/10.1016/S0885-2014(93)80003-C

Mandler, J. M., \& McDonough, L. (1996). Drinking and driving don't mix: inductive generalization in infancy. Cognition, 59(3), 307-335. https://doi.org/10.1016/0010- 
0277(95)00696-6

Mandler, J. M., \& McDonough, L. (2000). Advancing downward to the basic level. Journal of Cognition and Development, 1(4), 379-403. https://doi.org/10.1207/S15327647JCD0104_02

Markman, E. M. (1989). Categorization and naming in children: problems of induction. The MIT Press.

McDonough, L., \& Mandler, J. M. (1998). Inductive generalization in 9- and 11-month-olds. Developmental Science, 1(2), 227-232. https://doi.org/10.1111/1467-7687.00035

Medin, D. L., Lynch, E. B., Coley, J. D., \& Atran, S. (1997). Categorization and reasoning among tree experts: Do all roads lead to Rome? Cognitive Psychology, 32(1), 49-96. https://doi.org/10.1006/cogp.1997.0645

Mithöfer, A., \& Boland, W. (2012). Plant defense against herbivores: chemical aspects. Annual Review of Plant Biology, 63(1), 431-450. https://doi.org/10.1146/annurevarplant-042110-103854

Nazzi, T., \& Gopnik, A. (2001). Linguistic and cognitive abilities in infancy: When does language become a tool for categorization? Cognition, 80(3), B11-20. https://doi.org/10.1016/S0010-0277(01)00112-3

Oña, L., Oña, L. S., \& Wertz, A. E. (2019). The evolution of plant social learning through error minimization. Evolution and Human Behavior. https://doi.org/10.1016/j.evolhumbehav.2019.05.009

Oppenheimer, D. M., Meyvis, T., \& Davidenko, N. (2009). Instructional manipulation checks: detecting satisficing to increase statistical power. Journal of Experimental Social Psychology, 45(4), 867-872. https://doi.org/10.1016/j.jesp.2009.03.009

Palo, R. T., \& Robbins, C. T. (1991). Plant defenses against mammalian herbivory. CRC Press. 
Pauen, S. (2002). Evidence for knowledge-based category discrimination in infancy. Child Development, 73(4), 1016-1033. https://doi.org/10.1111/1467-8624.00454

Perry, S. (2011). Social traditions and social learning in capuchin monkeys (Cebus). Philosophical Transactions of the Royal Society B: Biological Sciences, 366(1567), 988-996. https://doi.org/10.1098/rstb.2010.0317

Placek, C. D., \& Hagen, E. H. (2015). Fetal protection. Human Nature, 26(3), 255-276. https://doi.org/10.1007/s12110-015-9239-2

Placek, C. D., Madhivanan, P., \& Hagen, E. H. (2017). Innate food aversions and culturally transmitted food taboos in pregnant women in rural southwest India: Separate systems to protect the fetus? Evolution and Human Behavior, 38(6), 714-728. https://doi.org/10.1016/j.evolhumbehav.2017.08.001

Profet, M. (1992). Pregnancy sickness as adaptation: a deterrent to maternal ingestion of teratogens. In The adapted mind: Evolutionary psychology and the generation of culture (pp. 327-365). Oxford University Press.

Ralph, M. A. L., Howard, D., Nightingale, G., \& Ellis, A. W. (1998). Are living and nonliving category-specific deficits causally linked to impaired perceptual or associative knowledge? Evidence from a category-specific double dissociation. Neurocase, 4(45), 311-338. https://doi.org/10.1080/13554799808410630

Rakison, D. H., \& Butterworth, G. A. M. (1998). Infants' attention to object structure in early categorization. Developmental psychology, 34(6), 1310-1325. https://doi.org/10.1037//0012-1649.34.6.1310

Rioux, C. (2019). Food neophobia in childhood. In H. L. Meiselman (Ed.), Handbook of eating and drinking: interdisciplinary perspectives (pp. 1-20). Springer International Publishing. https://doi.org/10.1007/978-3-319-75388-1_159-1

Rogers, T. T., \& McClelland, J. L. (2005). A parallel distributed processing approach to 
semantic cognition: applications to conceptual development. In L. Gershkoff-Stowe \& D. H. Rakison (Eds.), Building object categories in developmental time (pp. 335-387). Lawrence Erlbaum Associates Publishers.

Ross-Sheehy, S., Oakes, L. M., \& Luck, S. J. (2003). The development of visual short-term memory capacity in infants. Child Development, 74(6), 1807-1822. https://doi.org/10.1046/j.1467-8624.2003.00639.x

R Core Team (2018) R: a language and environment for statistical computing. R Foundation for Statistical Computing, Vienna.

Ross, N., Medin, D., Coley, J. D., \& Atran, S. (2003). Cultural and experiential differences in the development of folkbiological induction. Cognitive Development, 18(1), 25-47. https://doi.org/10.1016/S0885-2014(02)00142-9

Rozin, P., \& Kalat, J. W. (1971). Specific hungers and poison avoidance as adaptive specializations of learning. Psychological Review, 78(6), 459-486. https://doi.org/10.1037/h0031878

Rumiati, R. I., \& Foroni, F. (2016). We are what we eat: how food is represented in our mind/brain. Psychonomic Bulletin \& Review, 23(4), 1043-1054. https://doi.org/10.3758/s13423-015-0908-2

Saffran, J. R., Pollak, S. D., Seibel, R. L., \& Shkolnik, A. (2007). Dog is a dog is a dog: infant rule learning is not specific to language. Cognition, 105(3), 669-680. https://doi.org/10.1016/j.cognition.2006.11.004

Setoh, P., Wu, D., Baillargeon, R., \& Gelman, R. (2013). Young infants have biological expectations about animals. Proceedings of the National Academy of Sciences, 110(40), 15937-15942. https://doi.org/10.1073/pnas.1314075110

Sloutsky, V. M. (2003). The role of similarity in the development of categorization. Trends in Cognitive Sciences, 7(6), 246-251. https://doi.org/10.1016/S1364-6613(03)00109-8 
Smith, L. B. (2005). Emerging ideas about categories. In L. Gershkoff-Stowe \& D. H. Rakison (Eds.), Building object categories in developmental time (pp. 159-173). Lawrence Erlbaum.

Smith, L. B., Jones, S., \& Landau, B. (1996). Naming in young children: a dumb attentional mechanism? Cognition, 60(2), 143-171. https://doi.org/10.1016/0010-0277(96)007093

Spelke, E. S., Phillips, A., \& Woodward, A. L. (1995). In Sperber, D., Premack, D. \& Premack, A. (Eds.), Infants' knowledge of object motion and human action. In Causal cognition: A multidisciplinary debate (pp. 44-78). Clarendon Press/Oxford University Press.

Szagun, G., Stumper, B., \& Schramm, S. A. (2009). Fragebogen zur frühkindlichen Sprachentwicklung FRAKIS (Standardform) und FRAKIS-K (Kurzform). Pearson.

Truxaw, D., Krasnow, M. M., Woods, C., \& German, T. P. (2006). Conditions under which function information attenuates name extension via shape. Psychological Science, 17(5), 367-371. https://doi.org/10.1111/j.1467-9280.2006.01713.x

Wertz, A. E. (2019). How plants shape the mind. Trends in Cognitive Sciences. https://doi.org/10.1016/j.tics.2019.04.009

Wertz, A. E., \& Wynn, K. (2014a). Thyme to touch: infants possess strategies that protect them from dangers posed by plants. Cognition, 130(1), 44-49. https://doi.org/10.1016/j.cognition.2013.09.002

Wertz, A. E., \& Wynn, K. (2014b). Selective social learning of plant edibility in 6- and 18month-old infants. Psychological Science, 25(4), 874-882. https://doi.org/10.1177/0956797613516145

Wertz, A. E., \& Wynn, K. (2019). Can I eat that too? 18-month-olds generalize social information about edibility to similar looking plants. Appetite, 138, 127-135. 
https://doi.org/10.1016/j.appet.2019.02.013

Włodarczyk, A., Elsner, C., Schmitterer, A., \& Wertz, A. E. (2018). Every rose has its thorn: infants' responses to pointed shapes in naturalistic contexts. Evolution and Human Behavior, 39(6), 583-593. https://doi.org/10.1016/j.evolhumbehav.2018.06.001

Włodarczyk, A., Rioux, C., \& Wertz, A. E. (2020). Social information reduces infants’ avoidance of plants. Cognitive Development, 54, 100867. https://doi.org/10.1016/j.cogdev.2020.100867

Woodward, A. L. (1998). Infants selectively encode the goal object of an actor's reach. Cognition, 69(1), 1-34. https://doi.org/10.1016/s0010-0277(98)00058-4 